\section{OC-056 TEMPORARY GASTRO-ELECTRICAL STIMULATION IMPROVES GASTRIC EMPTYING AND QUALITY OF LIFE IN PATIENTS WITH REFRACTORY GASTROPARESIS}

doi:10.1136/gut.2011.239301.56 overall well-being on a scale of -3 (worst) to +3 (best). Nausea and vomiting were judged by patients on a scale of 0 (best) to 4 (worst).

Results Some 22 patients underwent insertion of a temporary GES electrode with no associated morbidity. Median patient age was 41 (17-62). 17 of the 22 cases of gastroparesis were idiopathic in nature, 3 were post-surgical and 2 were diabetic. Gastric isotope emptying time ( $\mathrm{t} 1 / 2)$ improved in $16 / 22$ patients $(73 \%)$. The median (interquartile range) pre-operative gastric isotope emptying time ( $\mathrm{t} 1 / 2)$ (minutes) was 251 (139.5-388.5) versus 100.5 (45.5-137) post-operatively $(\mathrm{p}=0.005)$.

The overall score of well-being improved in $18 / 19$ patients $(95 \%)$. The median pre-procedure score was -3 versus 2 postprocedure $(p<0.001)$. Symptoms of vomiting improved in 14 of 19 patients $(74 \%)$. Median vomiting score was 3 pre-operatively versus 0 post-operatively $(p<0.001)$. Symptoms of nausea improved in all 18 patients completing this aspect of the questionnaire with the median score pre-procedure 3 versus 0.5 post-procedure $(\mathrm{p}<0.001)$. Symptoms of pain, early satiety and bloating also demonstrated improvement post procedure. Conclusion Temporary GES improves gastric emptying, symptoms and perception of well-being in patients with refractory gastroparesis. The longer-term outcome of permanent GES in these patients is yet to be confirmed.

Competing interests None.

Keywords gastroparesis.

S Gibson, ${ }^{1, *}$ L Clark, ${ }^{2} \mathrm{~N}$ Jamieson, ${ }^{2}$ G Fullarton ${ }^{1}$ Department of Upper GI Surgery, Glasgow Royal Infirmary, UK; ${ }^{2}$ Department of Gastroenterology, Stobhill Hospital, Glasgow, UK

Introduction Gastro-electrical stimulation (GES) is an accepted method of managing severe drug refractory gastroparesis. Temporary GES may help select which patients would most benefit from the permanent GES treatment; however, data on the practicality and efficacy of temporary GES are lacking. The aim of this study was to determine the efficacy of temporary GES in patients with refractory gastroparesis.

Methods Patients with confirmed drug refractory gastroparesis $\left(t \frac{1}{2}>90 \mathrm{~m}\right)$ were selected for temporary GES. Preprocedure gastric isotope emptying data, and visual analogue symptom score were prospectively gathered. A temporary GES electrode (model 6414-200 Medtronic Ltd) was inserted endoscopically into the gastric antrum and secured with an Olympus Quickclip (Olympus Corp). Electrodes were then secured trans-nasally and connected to an external GES device (Enterra, Medtronic Ltd) set at $14 \mathrm{~Hz}$ frequency and standard amplitude (5-10 mA). Post-procedure gastric isotope emptying studies were repeated on day 4 and patients provided daily symptom scores on a visual analogue scale. Patients scored 